YAJUAN DENG, Ph.D. ${ }^{1}$

E-mail: yjdeng@chd.edu.cn

TING WANG, Ph.D. Candidate ${ }^{2}$

(Corresponding author)

E-mail: wangtingp@163.com

RUI MA, Ph.D. ${ }^{3}$

E-mail:drma@ucdavis.edu

${ }^{1}$ Department of Traffic Engineering,

School of Highway, Chang'an University

Middle of South 2nd-ring Road, Xi'an, Shaanxi,

710064, China

2 School of Transportation, Southeast University

Road of Southeast University 2, Nanjing, Jiangsu,

211189, China

${ }^{3}$ Department of Civil and Environmental Engineering

University of California, Davis

1001 Ghausi Hall, One Shield Ave, Davis, CA 95616, USA
Traffic in the Cities Original Scientific Paper Submitted: 9 Mar. 2018 Accepted: 5 Feb. 2019

\title{
ACCEPTABLE THRESHOLD OF PARKING CHARGES FOR URBAN ELECTRIC BICYCLES
}

\begin{abstract}
Electric bicycles are one of the essential traffic modes in many cities in China. Due to the consideration on safety and efficiency of the urban transportation systems, it is recognized that the use of electric bicycles should be limited by shifting the demand towards public transit by imposing parking charges on electric bicycles. To plan for this, the travellers' acceptance of parking charges must be taken into account. This paper proposes an acceptable threshold Logit model based on the non-compensation theory to calculate the threshold of the parking charge of electric bicycles. Electric bicycle trips are categorized into seven groups in terms of travel distances. The parking charges are of four discrete levels, from 0, 1, 2 to 3 yuan. Based on the survey data in the city of Handan, the traditional and acceptable threshold Nest-Logit models with the distance intervals and charges have been established and calibrated. Model calibration results show that the acceptable threshold Nest-Logit model is more accurate than the traditional Nest-Logit model, and the parking charge thresholds do exist. Specifically, within 3 $\mathrm{km}$ and outside $3 \mathrm{~km}$ the parking charge threshold is 1 yuan and 2 yuan, respectively. The parking charge thresholds can help in decision-making for parking pricing of electric bicycles.
\end{abstract}

\section{KEY WORDS}

urban traffic; threshold; Nest-Logit model; electric bicycle; parking charge;

\section{INTRODUCTION}

Electric bicycles (e-bikes) are two-wheeled vehicles powered by electric motor and battery. According to the National Bureau of Statistics, there were over 200 million electric bicycles in China in 2016. Electric bicycles were once very popular for their flexibility and convenience in many cities. However, the National Road Transportation Law [1] classifies the electric bicycle as a non-motor vehicle from legal and regulatory perspective and allows access to bicycle infrastructure. Consequently, safety problems such as speeding, overloading, occupying roadways, even riding on expressway, poor stability, changing directions randomly, contributing to congestion are serious. According to Shanghai traffic police department statistics, in non-motor vehicle accidents, electric bicycles accounted for more than $80 \%$ from January to September in 2017. According to Nanning traffic police department statistics, there were 2,778 traffic accidents involving electric bicycles which resulted in 28 deaths and 604 injuries in 2017. Moreover, in all traffic accidents of Nanning, the number of accidents, the number of deaths and the number of injuries associated with electric bicycles belong all in the top three.

So, local policies have been critical to the development of electric bicycles. Beijing introduced a ban on electric bicycles in early 2006 , which was quickly withdrawn. However, on a part of the streets the electric bicycle has been prohibited again since 2016. Guangzhou also introduced a ban on electric bicycles in late 2006. Chengdu and Fuzhou have announced a licensing scheme that will restrict the use of electric bicycles in the city centre based on the size and speed characteristics. Shenzhen plans to ban electric bicycles in the developed areas of public transportation and key areas. However, it is impossible to eliminate electric bicycles in the cities in short term, because electric bicycles play an important role in the improvement of mobility and accessibility. It is necessary to limit the 
use of electric bicycles by parking charges and to develop the alternative traffic modes such as public bicycles, sharing bicycles and buses to gradually eliminate electric bicycles.

The existing research on parking charges focuses mainly on private cars. To mitigate the traffic congestion and reduce total social costs, a model was established to determine the parking charges and parking supply [2]. To compare the attitudes towards congestion and parking charge and explore their effect on travel behaviour, two Logit models were established [3]. Hensher et al. and Pierce et al. [4-5] measured the effect of parking prices on the parking occupancy. Based on the stated preference data and logistic regression, a model was developed to predict the effects of the parking price on time limitation [6]. Based on the structural equation theory, a model on the influence factors related to the acceptability of parking charges was established [7]. Gillen et al., Wilson et al., Peng et al. and Qin et al. [8-11] analysed the relationship between the parking price and the mode choice. Hypo-best price model of on-street parking charge was constructed which emphasises the policy factors of on-street parking in terms of the public feature of onstreet parking space [12].

Even though parking charges are affected by many factors, it is undeniable that travellers' acceptance of parking charge must be taken into account. The travel choice behaviour will suffer unconventional changes when the parking fee is beyond the accepted price threshold of the travellers. Although some researchers have realised the importance of attribute threshold in travel choice behaviour, almost all the studies failed to mention how to determine the threshold. Kishi's Logit price sensitivity measurement (KLP) is often employed to obtain the price threshold of the consumer, which determines the price threshold according to the consumers' psychological reaction and cumulative probability distribution curve [13]. As well known the charge price can affect the travel behaviour, consequently, charge pricing ignoring the travel choice behaviour is too one-sided. In this paper, an attempt is made to estimate reversely the price threshold according to travel choice behaviour statistics results. Logit model can be used to analyse the travel choice behaviour; however, when the value of attributes exceeds the traditional Logit model can lead to errors in estimation [14]. Therefore, a semi-compensatory discrete choice model with explicit attribute thresholds of perception was established [15], and the difference between traditional discrete choice model and the semi-compensatory discrete choice model considering threshold of attributes has been discussed. Considering the thresholds in the perception of changes in attribute values, a discrete model was established. The model postulates that if thresholds exist they could be random, differ between individuals, and they could even be a function of socio-economic characteristics and choice conditions. Further, with the given thresholds the difference between traditional discrete choice model and the proposed model has been discussed [16]. Obermeyer pointed out that the value of travel time savings will be biased if the time threshold is ignored in the route choice model [17]. Based on the route choice data from a real-world driving experiment, an analysis was conducted to observe the frequency of different choice strategies, examine the route switching behaviour and inertial choices. Finally, the inertia thresholds were estimated according to the lost travel time resulting from inertial choices [18].

In this paper, the accepted thresholds of parking charge have been analysed, which can be used for decision-making regarding parking pricing of electric bicycles, and an acceptable threshold Logit model has been established to determine the parking charge thresholds of the electric bicycles. Based on the data of the electric bicycles, public bicycles and buses in Handan, China, the traditional Nest-Logit (NL) models and acceptable threshold NL models have been calibrated. By comparing the precision of the models with different travel distances and charging levels, the parking charge thresholds have been determined.

\section{DATA COLLECTION}

The study area is Handan of China which is about $10 \mathrm{~km}$ from east to west and from north to south. The common traffic modes include electric bicycles, public bicycles, cars, taxis, buses and walking which account for $18 \%, 11 \%, 22 \%, 8 \%, 18 \%$, and $23 \%$, respectively (the data were acquired from the "Travel Survey Report of Handan in 2015”). By 2020, the sharing ratio of electric bicycles, public bicycles, cars, taxis, buses and walking will be $8 \%, 14 \%, 23 \%, 8 \%, 23 \%$, and $24 \%$, respectively (the data were acquired from "The 13th Five-Year Traffic developing planning of Handan City"). It intends to reduce the use of electric bicycles in the central areas by parking charging to $8 \%$ and to promote a larger number of people transferring to buses and public bicycles. This paper aims to determine the parking charge thresholds of electric bicycles to limit their use and to find the alternative modes.

As is well known, walking, bicycles, electric bicycles, buses, bus rapid transit (BRT), subway, cars and taxis have their own ideal travel distances, which is illustrated in Figure 1 [19-20]. From this figure, it can be seen that the reasonable travel distance of electric bicycles is about $6 \mathrm{~km}$. Consequently, this paper divides the travel distances into two parts: within $6 \mathrm{~km}$ and outside $6 \mathrm{~km}$. Furthermore, a detailed division is considered when the travel distance is within $6 \mathrm{~km}$. The process of traffic modes choice can be divided into the first and the second level. Electric bicycles, cars and walking belong to private traffic modes, and public 


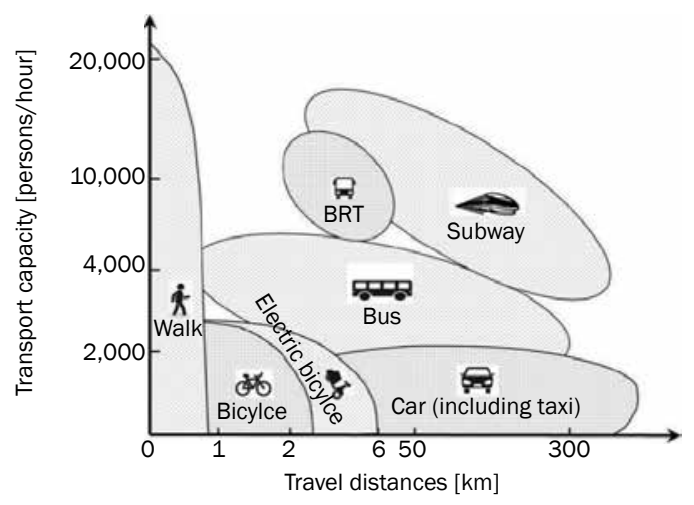

Figure 1 - Reasonable travel distances of different traffic modes

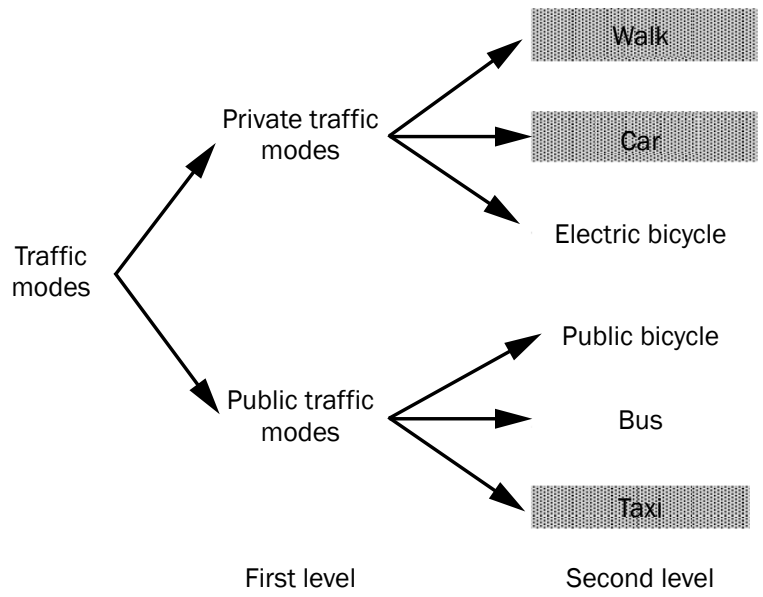

Figure 2 - Traffic mode choice limbs distribution

bicycles, buses and taxis belong to public traffic modes. The traffic mode choice limbs which compete with the electric bicycles include public bicycles and buses, as shown in Figure 2. Walking, cars and taxis will not be considered due to reasonable travel distances, ownership and cost.

Data collection is conducted through a questionnaire, in which the data are divided into three categories: RP data which are mainly used for the status analysis of the traffic mode choice, SP data which are mainly used for model calibration and personal attribute data. In the RP survey, the respondents' travel distance and traffic mode choice have been obtained; further, if one uses more than one traffic mode, the travel distance of each mode is collected. In our SP survey, the service level index has been the parking charge value including four discrete levels from 0, 1, 2 to 3 yuan and travel distance which has been categorized into seven groups including less than $1 \mathrm{~km}, 1-2$ $\mathrm{km}, 2-3 \mathrm{~km}, 3-4 \mathrm{~km}, 4-5 \mathrm{~km}, 5-6 \mathrm{~km}$ and out of $6 \mathrm{~km}$. The personal attributes include: gender, age, education level, car ownership and monthly income. In the survey, the age has been divided into four categories, including 18 to 30,31 to 40,41 to 50 , and older than 50. The education level includes four categories, under junior high school, high school, university and post graduate. The average monthly income of Handan city is CNY 4,229 yuan (CNY 1 yuan equals about 0.1441 USD or 0.1258 EUR). Monthly income has been divided into four categories: less than CNY 4,000, 4,000 to $8,000,8,000$ to 12,000 yuan, and higher than 12,000 yuan. Considering the area characteristics of Handan and the habits of the residents, four representative commercial malls in the centre of Handan city, which include Xinshiji, Furuiteshidaiguangchang, Yangguangshimao and Wanda were surveyed.

Finally, we received 972 valid data. The statistical result indicates that the gender plays an important role in the mode choice. All different age groups tend to travel by electric bicycles, but there is a significant difference in the mode choice among the travellers of the age 18-30. Monthly income has effect on the mode choice, but the education level has little effect. Travellers are more likely to choose electric bicycles regardless of whether they own a car or not, but travellers who own cars show a significant difference in the tendency of the mode choice. There is a large change in the mode choice when the travel distance is different. Therefore, a preliminary assessment is made that the gender, 18-30 years old, monthly income, car ownership and travel distance are significant factors in the mode choice.

\section{METHODOLOGY}

\subsection{Basic model}

Pursuing the maximum utility is the core principle of disaggregate model, in which respondents are supposed to know all the information about the alternatives and follow the compensation theory. Considering the time and cost for traveller $n$, the utility function of mode $i$ is shown in Equation 1.

$U_{\text {in }}=V_{\text {in }}+\varepsilon_{\text {in }}=a \cdot \cos t_{i}+b \cdot$ time $_{i}+\varepsilon_{\text {in }}$

where: $U_{\text {in }}$ represents the utility of traveller $n$ when mode $i$ is selected; $V_{\text {in }}$ stands for the systematic part of the utility; $\varepsilon_{i n}$ is the error between the systematic part of utility and the true utility; $a, b$ is the coefficient of cost and time, respectively; cost $_{i}$, time $_{i}$ represent the time and cost of mode $i$.

Assume that there are two modes, cost and time are 2 yuan and $4 \mathrm{~min}$, respectively in mode 1 , cost and time are 6 yuan and 2 min, respectively in mode 2, $a=-1, b=-2$. Considering that two factors can be transformed mutually, both utilities equal -10 . Thus, the choice probability of these two modes is the same in traditional Logit model. However, this is unreasonable. Once the cost or time exceed the travellers' 
acceptable threshold $X^{\text {Ath }}$, they may give up on this mode, which means $U_{\text {in }}$ will be infinitely small. This situation is defined as "non-compensation theory" in utility calculation [21]. Due to the existence of non-compensation mechanisms, the traveller's actual choice is determined by Equation 2 .

$$
\left\{\begin{array}{l}
S_{1 n} \text { if } U_{1 n}>U_{2 n} ; \cos t_{1}<\cos t_{n}^{\text {Ath }} \text { and } \text { time }_{1}<\text { time } \\
S_{1 n} \text { if } U_{1 n}<U_{2 n} ; \cos t_{2} \geq \cos t_{n}^{\text {Ath }} \text { or } \text { time }_{2} \geq \text { time }_{n}^{\text {Ath }} \\
S_{2 n} \text { if } U_{2 n}>U_{1 n} ; \cos t_{2}<\cos t_{n}^{\text {Ath }} \text { and } \text { time }_{2}<\text { time }_{n}^{\text {Ath }} \\
S_{2 n} \text { if } U_{1 n}>U_{2 n} ; \cos t_{1} \geq \cos t_{n}^{\text {Ath }} \text { or } \text { time }_{1} \geq \text { time }_{n}^{\text {Ath }}
\end{array}\right.
$$

where: $S_{1 n}, S_{2 n}$ represent traveller $n$ choosing mode 1 or mode 2; time ${ }_{n}^{\text {Ath }}, \operatorname{cost}_{n}^{\text {Ath }}$ are acceptable thresholds of time or cost.

An acceptable threshold NL model is established based on the non-compensation theory and acceptable threshold. The model assumes that the acceptable threshold of attribute $X$ for traveller $n$ is $X_{n}^{A t h}$ and the utility error term for each alternative is subject to the standard extreme value distribution. According to the joint cumulative distribution function of modes, the choice probability $P\left(c_{i}\right)$ of mode $i$ is shown in Equation 3 when the coefficient of attribute in utility function is negative and Equation 4 when the coefficient of attribute in utility function is positive. The relationship between the utility and the attribute is linear, and the utility will be infinitely small when the value of attribute is larger or smaller than a certain value, which is consistent with the reality, as shown in Figure $3 a$ and Figure $3 b$. Without consideration of the threshold, the choice probability of mode is shown in Equation 5. The relationship between the utility and attribute is linear, too. However, the utility is infinitely small or infinitely large when the attribute value is infinitely large

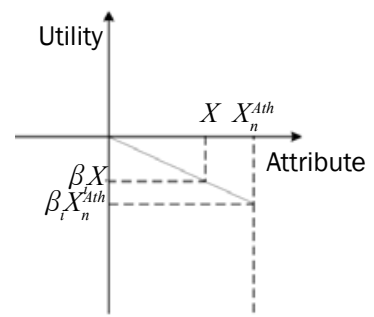

Figure $3 a-$ Attribute coefficient in utility function is negative

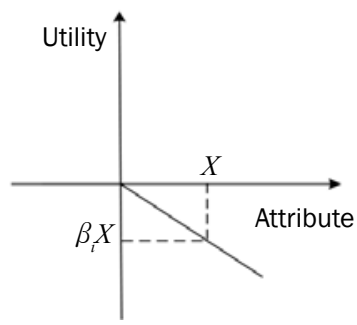

Figure 3c - Attribute coefficient in utility function is negative or infinitely small, shown in Figure $3 c$ and Figure $3 d$. Obviously, it is not consistent with the reality, especially when attributes such as time and cost are included in the utility.

$$
\begin{aligned}
& \begin{cases}P\left(c_{i}\right)=P(t) \cdot P\left(c_{i} \mid t\right)= & X<X_{n}^{\text {Ath }} \\
\frac{\exp \left[\lambda_{2}\left(V_{j}+V_{j}^{*}\right)\right]}{\sum_{j \in N_{t}} \exp \left[\lambda_{2}\left(V_{j}+V_{j}^{*}\right)\right]} \cdot \frac{\exp \left[\lambda_{1} V_{i}\right]}{\sum_{j \in N_{m}} \exp \left[\lambda_{1} V_{i}\right]} & \\
P\left(c_{i}\right)=0 & X \geq X_{n}^{\text {Ath }}\end{cases} \\
& \begin{cases}P\left(c_{i}\right)=P(t) \cdot P\left(c_{i} \mid t\right)= & X \geq X_{n}^{\text {Ath }} \\
\frac{\exp \left[\lambda_{2}\left(V_{j}+V_{j}^{*}\right)\right]}{\sum_{j \in N_{t}} \exp \left[\lambda_{2}\left(V_{j}+V_{j}^{*}\right)\right]} \cdot \frac{\exp \left[\lambda_{1} V_{i}\right]}{\sum_{j \in N_{m}} \exp \left[\lambda_{1} V_{i}\right]} & X<X_{n}^{\text {Ath }}\end{cases}
\end{aligned}
$$

$$
\begin{aligned}
& P\left(c_{i}\right)=P(t) \cdot P\left(c_{i} \mid t\right)= \\
& \quad \frac{\exp \left[\lambda_{2}\left(V_{j}+V_{j}^{*}\right)\right]}{\sum_{j \in N_{t}} \exp \left[\lambda_{2}\left(V_{j}+V_{j}^{*}\right)\right]} \cdot \frac{\exp \left[\lambda_{1} V_{i}\right]}{\sum_{j \in N_{m}} \exp \left[\lambda_{1} V_{i}\right]}
\end{aligned}
$$

where: $P(t)$ is the probability that nest $t$ has been selected; $P\left(c_{i} \mid t\right)$ represents the probability of mode $i$ when nest $i$ is selected; $N_{t}$ is the choice limb set of nest $t ; N_{m}$ is the selection set; $V_{j}$ is the system utility of the virtual choice $\operatorname{limb} j ; V_{j}^{*}$ is a variable, reflecting the influence of the sublayer to the upper layer; $V_{i}$ is the system utility of mode $i ; \lambda_{1}$ is a parameter corresponding to variance $\sigma_{1}^{2}$, which only takes the utility of the sublayer into consideration, and the default value is $1 ; \lambda_{2}$ represents the parameter corresponding to variance $\sigma_{2}^{2}$, considering the utility of the sublayer and the upper layer at the same time. Note that the model will change to MNL model when $\lambda_{2}=1$.

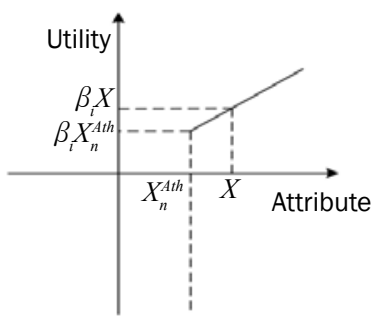

Figure $3 b$ - Attribute coefficient in utility function is positive

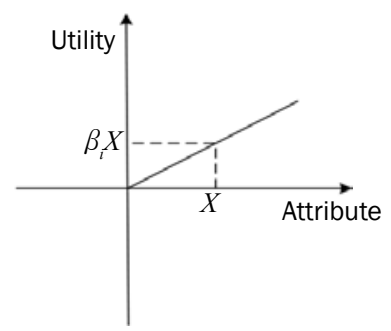

Figure $3 d$ - Attribute coefficient in utility function is positive 


\subsection{Threshold calculation procedure}

According to the calibration result of NL model, gender, age, monthly income, car ownership and travel distance play significant roles in the mode choice. Moreover, the factor elasticities show that the travel distance and parking charge have the most important effects on the mode choice. Consequently, the acceptable threshold NL models are established based on the travel distance. Traditional NL models are established based on the data of different travel distances, and the accepted threshold NL models are established based on the data of different travel distances with different parking charge thresholds. Eventually, the best parking charge threshold is recommended according to the accuracy of different models, and the calculation process of parking charge threshold is as follows: Step 1: According to the reasonable travel distance of the travel modes, travel distance $A$ is divided into seven sections which include less than $1 \mathrm{~km}, 1-2 \mathrm{~km}$, 2-3 km, 3-4 km, 4-5 km, 5-6 km and more than $6 \mathrm{~km}$, described as: $A=\left\{A_{1}, A_{2}, A_{3}, \ldots A_{7}\right\}$;

Step 2: Parking charge is divided into four levels which include 0 yuan, 1 yuan, 2 yuan and 3 yuan, and the parking charge thresholds are arranged from small to large, recorded as: $P=\left\{P_{1}, P_{2}, P_{3}, P_{4}\right\}$;

Step 3: Let $i=1, j=1$;

Step 4: The traditional NL model, recorded as $M_{i}$, is established based on the data that the travel distance is $A_{i}$ and the parking charge is $P_{j}$;

Step 5: Select $P_{j}(j \geq 2$, because it means no threshold exists when $j=1$ ) as the parking charge threshold. According to the traveller's choice behaviour to judge whether their behaviour is suitable for the acceptable threshold model to filter data (if the traveller chooses electric bicycle and the cost of electric bicycle parking is beyond or equal to the threshold, the data will not be chosen; otherwise, the data will be chosen). Then the accepted threshold model is calibrated according to the filtered data, recorded as $N_{j}$;

Step 6: Then $j=j+1$ and return to Step 5;

Step 7: When $j=4$, compare the precision of $M_{i}, N_{2}$, $N_{3}, N_{4}$, and the best model is selected as the final calibration result, and parking charge thresholds are obtained;

Step 8: Then let $i=i+1$ and return to Step 4;

Step 9: When $i=7$, calibration ends, and the parking charge thresholds of different travel distances are obtained.

\section{RESULT AND DISCUSSION}

\subsection{Traditional NL model}

The traditional NL model was established according to all the SP survey data and the calibration results are shown in Table 1.
If the absolute value of the t-test for the factor is greater than 1.96 in the calibration of NL model, there is a $95 \%$ confidence that the factor is a significant factor. The calibration results show that monthly income, gender, car ownership, age of 18-30, parking charge and travel distance are significant factors. Note that $\rho^{2}$ is less than 0.2 , which means the accuracy is low; however, $\lambda_{2}$ is 0.4235 , which indicates a high degree of correlation in the nest of the model and a reasonable relationship among each layer of the model.

Table 1 - Calibration results of traditional NL model

\begin{tabular}{|l|c|c||}
\hline \multirow{2}{*}{ Attribute } & \multicolumn{2}{|c|}{ Calibration coefficient (t test) } \\
\cline { 2 - 3 } & Sublayer & Upper layer \\
\hline \hline \multirow{2}{*}{ Constant } & $\begin{array}{c}0.2036 \\
(2.1236)\end{array}$ & $\begin{array}{c}0.2116 \\
(2.3125)\end{array}$ \\
\hline \multirow{2}{*}{ Monthly income } & $\begin{array}{c}-1.5865 \\
-2.9638)\end{array}$ & $\begin{array}{c}-1.9236 \\
(-3.1635)\end{array}$ \\
\hline \multirow{2}{*}{ Gender } & $\begin{array}{c}0.6521 \\
(2.5893)\end{array}$ & $\begin{array}{c}0.7231 \\
(2.6532)\end{array}$ \\
\hline \multirow{2}{*}{ Car ownership } & -0.6156 & -0.8309 \\
& $(-2.3682)$ & $(-2.1539)$ \\
\hline \multirow{2}{*}{ Age 18-30 } & 0.3513 & $\begin{array}{c}0.2836 \\
(2.6321)\end{array}$ \\
\hline \multirow{2}{*}{ Distance } & $(2.1752)$ & -4.1316 \\
& -2.2302 & $(-2.9632)$ \\
\hline \multirow{2}{*}{ Parking charge } & $(-3.2851)$ & -5.8127 \\
& - & $(-3.9352)$ \\
\hline \multirow{2}{*}{ Statistical indicators } & $\rho^{2}=0.1836$ & $\rho^{2}=0.1932$, \\
& & $\lambda=0.4235$ \\
\hline
\end{tabular}

Factor sensitivity can be measured using elasticities, defined as the percentage change in mode choice resulting from a $1 \%$ change in the factor, all else held constant. High elasticity value indicates that a relatively small change in the attribute causes a relatively large change in the mode choice. Low elasticity value means that the factor has relatively little effect on the mode choice [22]. For example, if the elasticity of electric bicycle ridership with respect to parking charge is -0.8 , this means that each $1 \%$ increase in the transit fares causes a $0.8 \%$ reduction in ridership. So, the elasticity of attribute to traffic mode can be calculated as shown in Equation 6. Taking a person with a monthly income of under 4,000 yuan, age 18-30, owning a car, travel distance 1-2 km, parking charge 1 yuan as an example, the elasticities have been calculated in Table 2.

$$
E_{X}^{P\left(c_{i}\right)}=\frac{\frac{d P\left(c_{i}\right)}{P\left(c_{i}\right)}}{\frac{d X}{X}}=\frac{X}{P\left(c_{i}\right)} \cdot \frac{d P\left(c_{i}\right)}{d X}
$$


where: $i$ represents traffic mode $i ; P\left(c_{i}\right)$ represents the probability that traffic mode $i$ is chosen; $X$ represents attribute $X ; E_{X}^{P(c i)}$ represents the elasticity of attribute $x$ to traffic mode $i$.

Based on the calibration results of the traditional NL model we can know the monthly income, gender, car ownership, age 18-30, distance and parking charge are significant factors (absolute values of t-test greater than 1.96); further, the greater the elasticity absolute value of the influencing factors, the greater the degree of influence, and the factor elasticities in Table 2 show that the travel distance and parking charge have the most important effects on mode choice. So, it is reasonable to determine the parking charge threshold based on the travel distance.

\section{Table 2 - Factor elasticities}

\begin{tabular}{||l|c||}
\hline \multicolumn{1}{|c|}{ Attribute } & Elasticities \\
\hline \hline Monthly income & -0.1429 \\
\hline Gender & 0.0926 \\
\hline Car ownership & -0.1326 \\
\hline Age 18-30 & 0.0711 \\
\hline Distance & -0.2932 \\
\hline Parking charge & -0.3619 \\
\hline
\end{tabular}

\subsection{Acceptable threshold NL model}

The acceptable threshold model is calibrated when the travel distance is within $1 \mathrm{~km}$, and the comparison of the calibration result between acceptable threshold NL model and traditional NL model (parking charge=0) is shown in Table 1 of the Appendix. Similarly, the calibration results with the distances of $1-2 \mathrm{~km}, 2-3 \mathrm{~km}$, 3-4 km, 4-5 km, 5-6 km and more than $6 \mathrm{~km}$ are obtained. The calibration results show that significant factors and their coefficients are similar between the models with travel distances of $1-2 \mathrm{~km}$ and $2-3 \mathrm{~km}$, and both of the parking thresholds equal 1 yuan. Consequently, the models are developed when the distance is $1-3 \mathrm{~km}$ and the results are shown in Table 2 of the Appendix. Similarly, significant factors and their coefficients are similar among the models with travel distances 3-4 km, 4-5 km and 5-6 km, and all of their parking thresholds equal 2 yuan. Consequently, a model is established when the distance is 3-6 km and the results are shown in Table 3 of the Appendix. As for the travel distance beyond $6 \mathrm{~km}$, the results are shown in Table 4 of the Appendix.

The calibration results show that if the traveller owns a private car, the probability and utility of the electric bicycle will decrease. Education level is not a significant factor in traditional NL model; however, the absolute values of $t$ test for the "Under junior high school" is greater than 1.96 in the acceptable threshold NL model; therefore, "Under junior high school" is a significant factor, which indicates that groups whose education level is under junior high school pay more attention to the charge threshold. The coefficient of the parking charge is negative, which means that with higher parking charges, the utility of electric bicycle tends to decline. There is a significant difference among different parking charges when the threshold is taken into consideration. Further, the threshold NL model is more accurate than the traditional NL model ( $\rho^{2}$ of threshold NL model is bigger), thus the parking charge thresholds do exist. The variation range of $\lambda_{2}$ is $0.4-0.5$ indicates that there is a high degree of correlation among limbs in the nest, and the relationship is reasonable. When the precision of the model is the highest, the charge value is recommended as the threshold, so the parking charge threshold within $3 \mathrm{~km}$ and outside $3 \mathrm{~km}$ is 1 yuan and 2 yuan, respectively.

\subsection{Sensitivity analysis}

Travellers' perception of the threshold is reflected by the coefficient of "parking charge" in threshold NL model, and the greater the absolute value of the coefficient, the higher the sensitivity to parking charge threshold. The coefficient of the parking charge with different travel distances is shown in Figure 4.

Figure 4 shows that when the travel distance is fixed, the threshold NL model in which the traveller has the highest sensitivity to the parking charge threshold has the highest acuracy, which further indicates that there is a parking charge threshold for the electric bicycle.

Cross-elasticities refer to the percentage change in the choice of a traffic mode resulting from a parking charge change in another related mode. For example, an increase in the price of riding electric bicycles tends to reduce the demand for electric bicycle and to increase the demand for bus and public bicycle. So, the

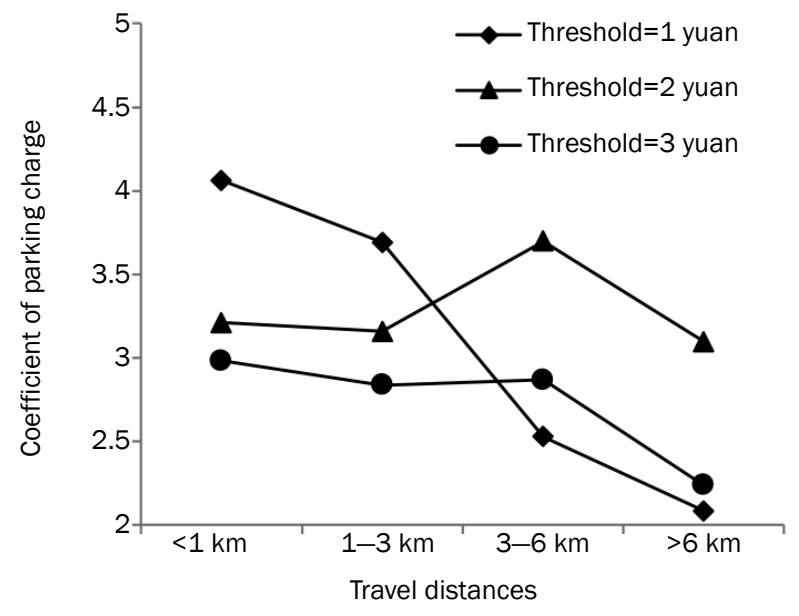

Figure 4 - Sensitivity analysis with different travel distances 
proportion change of mode $i$ resulting from the change of attribute $X_{j}$ to mode $j$ can be calculated as shown in Equation 7.

$$
E_{X_{i j}}^{P\left(c_{i}\right)}=\frac{\frac{d P\left(c_{i}\right)}{P\left(c_{i}\right)}}{\frac{d X_{j}}{X_{j}}}=\frac{X_{j}}{P\left(c_{i}\right)} \cdot \frac{d P\left(c_{i}\right)}{d X_{j}}
$$

where: $i$ and $j$ represent traffic mode $i$ and $j$, respectively; $P\left(c_{i}\right)$ and $P\left(c_{j}\right)$ represent the probabilities that traffic mode $i$ and $j$ are chosen, respectively; $X_{j}$ represents attribute $X_{j} ; E_{X_{i j}}^{P(c i)}$ represents the elasticity of attribute $X_{j}$ to traffic mode $i$.

According to the calibration results of Tables 1-4 in the Appendix, taking a person with a monthly income of under 4,000 yuan, 18-30 years of age, owning a car, educational level under junior high school, cross-elasticities were calculated with parking charge $=0.5$ yuan, 1 yuan, 1.5 yuan, 2 yuan, 2.5 yuan and 3 yuan, where EE represents the elasticity of the parking charge for electric bicycle; EP represents the cross-elasticity of parking charge for public bicycle; EB represents the cross-elasticity of parking charge for buses; PE represents the proportion of electric bicycle; PP represents the proportion of public bicycle; PB represents the proportion of buses. Moreover, based on the calibration parameters of the model with a travel distance within $1 \mathrm{~km}$ and parking charge threshold of 1 yuan, the proportion of traffic modes and elasticities under different parking charges can be obtained as shown in Figure $5 a$. Similarly, Figures $5 b, 5 c$ and $5 d$ can be obtained when the travel distance is $1-3 \mathrm{~km}$, with parking charge threshold of 1 yuan; 3-6 km with parking charge threshold 2 yuan, and outside $6 \mathrm{~km}$ with parking charge threshold 2 yuan, respectively.

Figures $5 a-5 d$ show when the parking charge of the electric bicycle is 0 yuan and travel distance is within $6 \mathrm{~km}$, travellers prefer to choose electric bicycles. With the increase of the parking charge, the number of public bicycle and bus travellers will increase gradually. Also, travellers are more inclined to choose public bicycles at distances smaller than $3 \mathrm{~km}$ and buses are more attractive when the distance exceeds $3 \mathrm{~km}$. When the travel distance is greater than $6 \mathrm{~km}$, travellers prefer to choose buses and the proportions of electric bicycles and public bicycles are low.

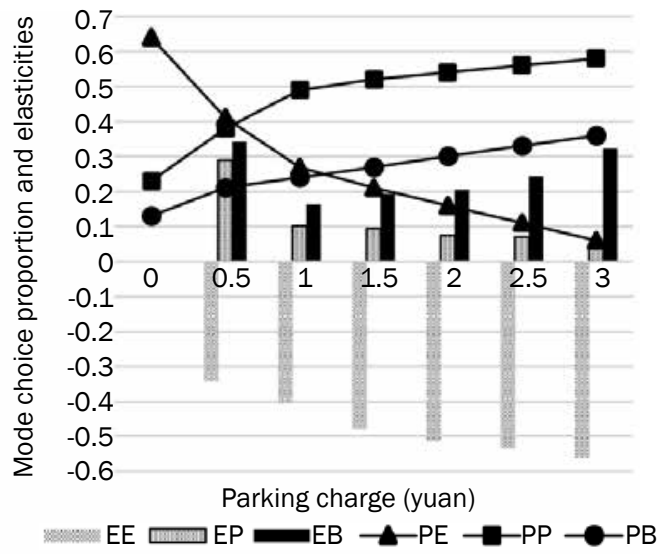

b) Distance from $1 \mathrm{~km}$ to $3 \mathrm{~km}$

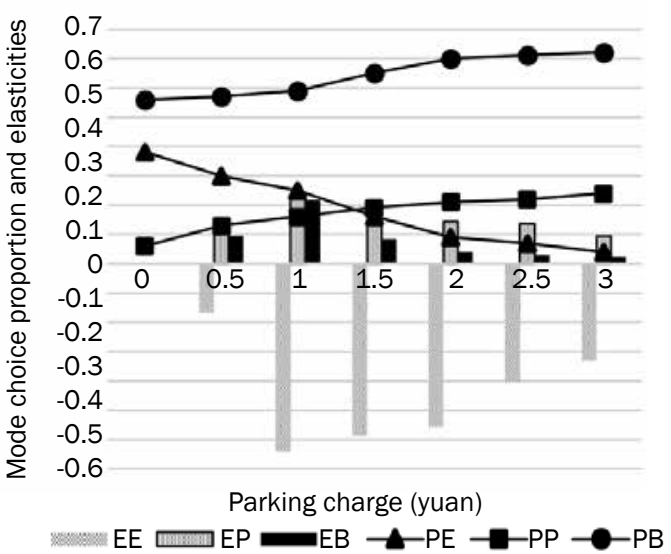

d) Distance outside $6 \mathrm{~km}$

c) Distance from $3 \mathrm{~km}$ to $6 \mathrm{~km}$

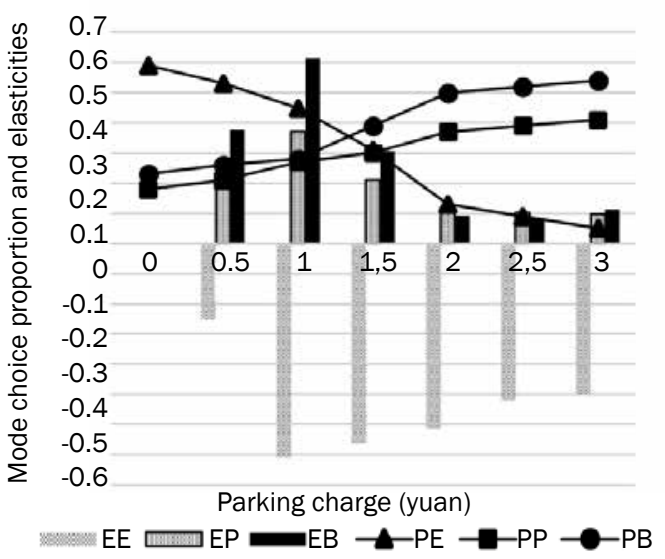

Figure 5 - Mode choice proportion and elasticities under different parking charges with different distances 
Figure 5a shows that when the parking charge is 0 yuan, the respondents prefer to choose electric bicycles and the proportion is very high. With the increase of the parking charge the proportion of electric bicycles decreases sharply and the proportion of public bicycles and buses features a greater growth. However, when the parking charge is more than 1 yuan, the trend is not obvious. Further, elasticities show that when the parking charge is 0.5 yuan, the elasticities of electric bicycles, public bicycles and buses are $-0.3864,0.2983$ and 0.4135 , respectively, which indicates that when the parking charge increases by 100 percent, that is, the parking charge is 1 yuan, electric bicycles will decrease by 38.64 percent and public bicycles and buses will increase by 29.83 percent and 41.35 percent, respectively. When the parking charge is over 1 yuan, the proportion of public bicycles and buses increases slowly. Comparing the variety of mode ratio and elasticity with different parking charges, it can be further certified that the parking charge threshold with travel distance within $1 \mathrm{~km}$ is 1 yuan. Similarly, from Figures $5 b-5 d$, it can be concluded that the parking charge thresholds are 1 yuan and 2 yuan, respectively, when the travel distance is smaller than 3 $\mathrm{km}$ and exceeding $3 \mathrm{~km}$.

To analyse the travellers' perception of the parking charge threshold clearly, the statistical analysis of the threshold value with different attributes is carried out. The analysis result with the travel distance smaller than $3 \mathrm{~km}$ and the parking charge threshold of 1 yuan is shown in Figure 6a. The analysis result with the travel distance of more than $3 \mathrm{~km}$ and the parking charge threshold of 2 yuan is shown in Figure $6 b$.

From the two figures some conclusions can be made. Women are more concerned about the parking charge threshold and the proportion of people considering parking charge threshold decreases with age, which may be due to the increase of the income. Education level plays a small role when parking charge threshold is 1 yuan, and there is no sufficient reason to indicate that education level plays an important role when parking charge threshold is 2 yuan. With monthly income increasing, there will be fewer travellers who consider thresholds. It is worth pointing out that Handan is a medium-sized city with steel and coal as important industries; therefore, the employees who entered the industry in the early stage are not necessarily educated, but their income is higher) so the positive correlation between education level and monthly income is not evident. The threshold plays an important role in determining the parking charge value, and the larger the area of the curve, the larger the population who consider parking charge threshold. Also, the more people who consider the parking charge threshold, the more instructive the threshold obtained for the formulation of the related charging policy.

\subsection{Suggested parking prices for electric bicycles}

By 2020 , the sharing ratio of electric bicycles, public bicycles, cars, taxis, buses and walking will be $8 \%$, $14 \%, 23 \%, 8 \%, 23 \%$, and $24 \%$, respectively. That is, by 2020 , the proportion of electric bicycles will have accounted for $17.8 \%$ of the sum of the three (electric bicycle, public bicycle and bus). Therefore, it is necessary to charge for electric bicycles to achieve the target sharing ratio. The pricing method based on the acceptable threshold is as follows:

Step 1: The attributes of traveller $n$ remain unchanged. Given the initial parking charge 1 yuan/time;

Step 2: Based on the model with travel distance smaller than $1 \mathrm{~km}$ and threshold 1 yuan/time, travel distance 1-3 km and threshold 1 yuan/time, travel distance 3-6 $\mathrm{km}$ and threshold 2 yuan/time, travel distance outside $6 \mathrm{~km}$ and threshold 2 yuan/time, the probability of the traveller who chooses an electric bicycle can be calculated. If the probability is greater than 0.33 , then it can be assumed that traveller $n$ will choose the electric bicycle. Next, calculate the total number of people and the sharing ratio of electric bicycle $\varphi_{1}$;

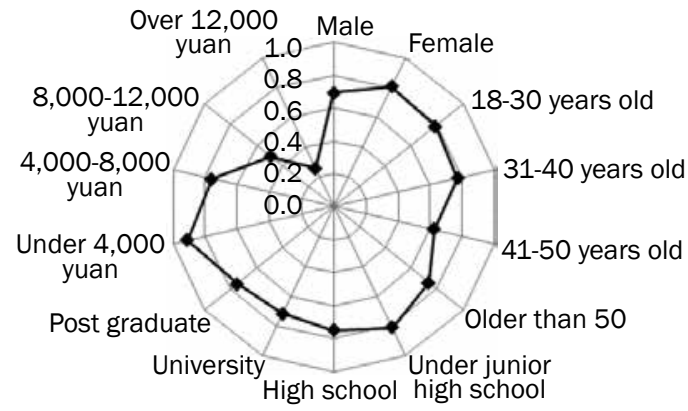

a) Threshold = 1 yuan

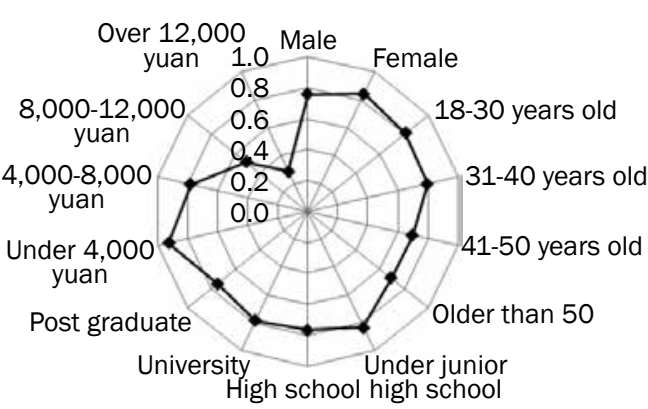

b) Threshold $=2$ yuan

Figure 6 - Analysis result of the threshold 
Step 3: Investigate the relationship between $\varphi_{1}$ and the target sharing ratio $\varphi=17.8 \%$;

- If $\varphi_{1}=\varphi$, then stop the calculation;

- If $\varphi_{1}>\varphi$, then the parking charge increment is set to $\Delta X=0.1$. Next, repeat Step 2 until $\varphi_{k-1}<\varphi_{k}<\varphi$ or $\varphi_{k-1}<\varphi<\varphi_{k}<\varphi+\delta$;

- If $\varphi_{1}<\varphi$, then the parking charge increment is set to $\Delta X=-0.1$. Next, repeat Step 2 until $\varphi_{k-1}<\varphi_{k}<\varphi$ or $\varphi_{k-1}<\varphi<\varphi_{k}<\varphi+\delta$; afterwards, $\varphi_{k-1}$ and $\varphi_{k}$ represent the sharing ratio when iterating at steps $k$-1 and $k$, respectively. $\delta$ indicates that the value of actual sharing ratio amount exceeds the target sharing ratio (the value is 0.003 in this study);

Step 4: Determine the suggested parking charge of electric bicycle based on the final charge value.

The calculation results show that when parking charges are 1.5 one parking and 1.6 one parking the sharing ratios of electric bicycles are $17.6 \%$ and $17.9 \%$, respectively, approximately to the target sharing ratio $17.8 \%$. To transfer more electric bicycles to buses and public bicycles, the suggested parking charge is 1.6 yuan one parking.

\section{CONCLUSION}

An acceptable threshold Logit model for determining the parking charge has been established based on the non-compensation theory and acceptable threshold. The data of electric bicycles, public bicycles and buses in Handan, China, have been applied to traditional NL models and acceptable threshold $\mathrm{NL}$ models, respectively. Comparing to the traditional NL mode, the results indicate that there is better precision in acceptable threshold NL model, and $\rho^{2}$ is greater than 0.2 . Also, the calibration results and elasticity analysis indicate that the parking charge thresholds do exist, and the parking charge threshold within $3 \mathrm{~km}$ and outside $3 \mathrm{~km}$ are 1 yuan and 2 yuan, respectively. The electric bicycle proportion decreases sharply when the parking charge value fluctuates around the threshold. Also, with the parking charge value increase, the travellers prefer to choose public bicycle and bus. Further, it has been observed that the travellers are more inclined to choose public bicycles with the distances smaller than $3 \mathrm{~km}$; otherwise, buses are more attractive. In terms of personal attributes, women are more concerned about the parking charge, and the education level plays a small role when parking charge threshold is 1 yuan. Furthermore, there is no sufficient reason to indicate that the education level plays an important role when parking charge threshold is 2 yuan. To transfer more electric bicycles to buses and public bicycles, the suggested parking charge is 1.6 yuan/one parking.

The accepted threshold model can estimate reversely parking charge threshold according to travel choice behaviour statistics results, compared with the other method, which can better reflect the relationship between the charge threshold and travel choice behaviour. The acceptable threshold model can be also used in other cities where the electric bicycle still plays an important role, but the parameters such as interval division of travel distance and charge price should be adjusted. Once the model is used in the cars, the charge threshold is also affected by the parking time, parking location and some other attributes apart from the travel distance. Further, the idea of the proposed threshold model can be used in the calculation of the threshold in other fields such as walking and riding distance threshold in the subway station area.

Although the method of determining the parking charge threshold of electric bicycles is recommended, there are some difficulties that should be discovered before being applied to the real world, such as the statistics of the attribute distribution and travel distance distribution. Moreover, the method of determining the pricing of electric bicycles based on the threshold model needs to be further researched. Additionally, the traveller's behaviour will suffer a sharp change at the charge threshold point in the accepted threshold method. In reality, the traveller is hesitant around this threshold. Therefore, a more complex change curve can be assumed, such as hard threshold function, and it is a piecewise linear function, where the slope within the threshold area is zero, and the soft threshold function, where the slope increases continuously from zero to the limit of one.

\section{ACKNOWLEDGEMENT}

The research is supported by the Shaanxi Provincial Science and Technological Project (Grant No. 2017JM5104, 2015SF296) and the Fundamental Research Funds for the Central Universities of China (Grant No. 300102218410).

\section{邓亚娟}

Email: yjdeng@chd.edu.cn

长安大学公路学院, 陕西 西安, 710064

王亭 (通讯作者)

Email: wangtingp@163.com

东南大学交通学院, 江苏 南京, 211189

马点

Email:drma@ucdavis.edu

加利福尼亚大学戴维斯分校土木与环境工程系

1001 Ghausi Hall, One Shield Ave, Davis, CA 95616

城市电动自行车停车收费可接受阈值研究

\section{摘要}

在中国的许多城市, 电动自行车是非常重要的交通方 式。考虑到城市交通系统的安全性和效率, 通过对电动自 行车进行停车收费, 减少电动自行车出行, 逐步将其转 
向公共交通成为共识。在电动自行车停车定价时必须考 虑出行者对停车收费的可接受阈值。本文提出了一种基 于非补偿理论的可接受阈值Logit模型来计算电动自行车 停车收费阈值。将电动自行车出行按出行距离分为 7 组, 停车费分为四个级别: 0 元、1元、2元到 3 元。以邯䣋市 出行者的调查数据为基础, 分别建立了传统Nest-Logit模 型及不同距离、不同收费水平下可接受阈值Nest-Logit模 型。模型标定结果表明: 可接受阈值Nest-Logit模型比传 统Nest-Logit模型精确度更高、停车收费阈值确实存在; 出行距离为 $3 \mathrm{~km}$ 以内和 $3 \mathrm{~km}$ 以外的停车收费阈值分别为 1 元和 2 元。确定的停车收费阈值有助于电动自行车停车定 价策略的制定。

\section{关键词}

城市交通; 阈值; Nest-Logit模型; 电动自行车; 停车收 费

\section{REFERENCES}

[1] China Central Government. National Road Transportation Law; 2004.

[2] Qian Z-S, Xiao F-E, Zhang H-M. Managing morning commute traffic with parking. Transportation Research Part B: Methodological. 2012;46(7): 894-916. Available from: doi:10.1016/j.trb.2012.011

[3] Albert G, Mahalel D. Congestion tolls and parking fees: A comparison of the potential effect on travel behavior. Transport Policy. 2006;13(6): 496-502. Available from: doi:10.1016/j.tranpol.2006.05.007

[4] Hensher DA, King J. Parking demand and responsiveness to supply, pricing and location in the Sydney central business district. Transportation Research Part A: Policy and Practice. 2001;35(3): 177-196. Available from: doi:10.1016/S0965-8564(99)00054-3

[5] Pierce G, Shoup D. Getting the prices right: an evaluation of pricing parking by demand in San Francisco. Journal of the American Planning Association. 2013;79(1): 67-81. Available from: doi:10.1080/019 44363.2013.787307

[6] Simićević J, Vukanović S, Milosavljević N. The effect of parking charges and time limit to car usage and parking behaviour. Transport Policy. 2013;30: 125-131. Available from: doi:10.1016/j.tranpol.2013.09.007

[7] Xiao H-H, Lu J, Ma Q, Wu Y, Lin Y-Q. Acceptability Analysis of Parking Charges Based on Structural Equation Model. Applied Mechanics and Materials. Trans Tech Publications. 2014;505: 1204-1210. Available from: doi:10.4028/www.scientific.net/AMM.505-506.1204

[8] Gillen DW. Effects of parking costs on urban transport modal choice. Transportation Research Record. 1977;637. Available from: http://worldcat.org/ isbn/0309026644

[9] Wilson RW. Estimating the travel and parking demand effects of employer-paid parking. Regional Science and Urban Economics. 1992;22(1): 133-145. Available from: doi:10.1016/0166-0462(92)90029-Z

[10] Peng Z, Dueker K, Strathman J. Residential location, employment location, and commuter responses to parking charges. Transportation Research Record: Journal of the Transportation Research Board. 1996;1556: 109-118. Available from: doi:10.3141/ 1556-13

[11] Qin H, Guan H-Z, Yin H-H. A study of the effect of parking price on the mode of inhabitant trip behavior-with the cars, public transit and taxi in Beijing as an example. China Civil Engineering Journal. 2008;41(8): 93-98. Available from: doi:10.15951/j.tmgcxb.2008.08.003

[12] An S, Ma T-C, Yin J-R. Parking fee pricing model for urban cities in China. Journal of Harbin Institute of Technology. 2000;32(2): 65-69.

[13] Kishi K, Uchida KE, Satoh K. Price sensitivity of airfare from the viewpoint of passengers. Infrastructure Planning Review. 1999;16: 187-194. Available from: doi:10.2208/journalip.16.187

[14] Cantillo V, Amaya J, de Dios Ortúzar J. Thresholds and indifference in stated choice surveys. Transportation Research Part B: Methodological. 2010;44(6): 753763. Available from: doi:10.1016/j.trb.2009.12.003

[15] Cantillo V, de Dios Ortúzar J. A semi-compensatory discrete choice model with explicit attribute thresholds of perception. Transportation Research Part B: Methodological. 2005;39(7): 641-657. Available from: doi:10.1016/j.trb.2004.08.002

[16] Cantillo V, Heydecker B, de Dios Ortúzar J. A discrete choice model incorporating thresholds for perception in attribute values. Transportation Research Part B: Methodological. 2006;40(9): 807-825. Available from: doi:10.1016/j.trb.2005.11.002

[17] Obermeyer A, Treiber M, Evangelinos C. Thresholds in choice behaviour and the size of travel time savings. arXiv preprint. arXiv:1402.3433, 2014. Available from: https://www.researchgate.net/publication/260211757

[18] Vreeswijk JD, van Berkum EC, van Arem B. Analysis of inertia thresholds based on real-world route choice data. Proceedings of the TRAIL Congress, 13 November 2014, Delft, Netherlands. Delft, Netherlands: TRAIL; 2014. p. 1-21.

[19] Huang S-S, Song R, Tao Y. Behavior of urban residents travel mode choosing and influencing factors: taking Beijing as an example. Communications Standardization. 2008;9: 124-128.

[20] Luo H-X. Study on locating and planning of urban public bike rental station. MS thesis. Beijing, Beijing Jiaotong University; 2013.

[21] Tversky A. Elimination by aspects: A theory of choice. Psycological Review. 1972;79(4): 281-299. Available from: doi:10.1037/h0032955

[22] Litman T. Transit price elasticities and cross-elasticities. Journal of Public Transportation. 2004;7(2): 3758. Available from: http://citeseerx.ist.psu.edu/viewdoc/summary?doi=10.1.1.300.1672 


\section{Appendix}

\section{Questionnaire on the Travellers' Choice Behaviour of Electric Bicycles in Handan City}

Hello, this questionnaire is conducted in order to better understand the characteristics of urban traveler's choice behavior for electric bicycle and develop a reasonable pricing method. We promise that your answers will only be used for data analysis. Thank you so much for your cooperation.

\section{Please answer the following questions (1-8) according to your actual situation.}

1. What gender are you?
Male
OFemale

2. How old are you?

○18-30 years old $\bigcirc 31-40$ years old $\bigcirc 41-50$ years old $\bigcirc$ Older than 50

3 . How much is your monthly income?
Under 4,000 yuan
4,000 - 8,000 yuan
8,000-12,000 yuan
Over 12,000 yuan

4 . What is your highest level of education?

Under junior high school

High school

University

Post graduate

5. Do you have your own car?

OYes

ONo

6. How far would you like to go during this trip?
$\bigcirc$ Less than $1 \mathrm{~km}$
1-2 km
$2-3 \mathrm{~km}$
3-4 km
- $4-5 \mathrm{~km}$
$5-6 \mathrm{~km}$

More than $6 \mathrm{~km}$

7. Which traffic mode did you choose during this trip? (more than one answer)
Electric bicycle
Bus
OPublic bicycle

If you chose more than one kind of traffic mode, what is the distance for each of them?
( ) $\mathrm{km}$ for electric bicycle
( $\quad$ km for bus

( ) $\mathrm{km}$ for public bicycle

8 . How long is your parking time?
$\bigcirc$ Less than 1 hour
1-2 hours

2-3 hours

More than 3 hours

If you used electric bicycle only, please answer the following questions (9-11) according to your actual situation.

\begin{tabular}{|c|c|c|}
\hline \multirow{2}{*}{9} & If the parking charge for electric bicycle is 1 yuan/time, would you still choose it to travel? \\
\cline { 2 - 3 } & OYes & ONo \\
\hline
\end{tabular}

\begin{tabular}{|c|cc|}
\hline \multirow{2}{*}{10} & If the parking charge for electric bicycle is 2 yuan/time, would you still choose it to travel? \\
\cline { 2 - 3 } & OYes & ONo \\
\hline
\end{tabular}

\begin{tabular}{|l|l|}
\hline \multirow{2}{*}{11} & If the parking charge for electric bicycle is 3 yuan/time, would you still choose it to travel? \\
\cline { 2 - 3 } & OYes ONo \\
\hline
\end{tabular}




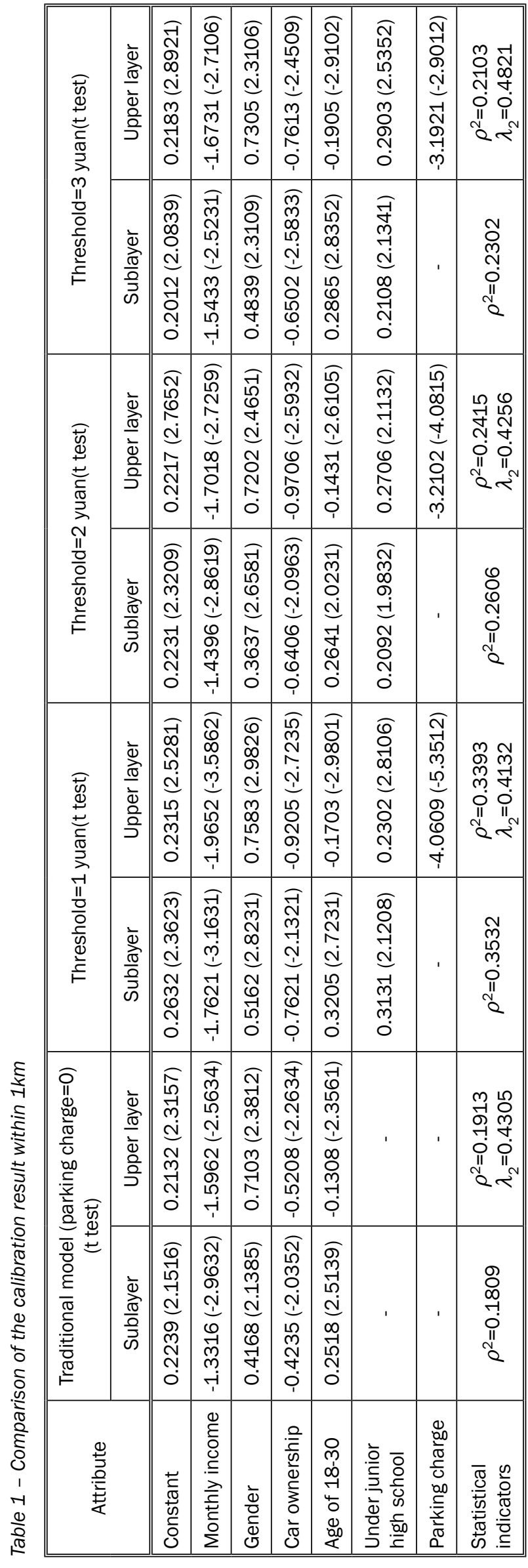

\begin{tabular}{|c|c|c|c|c|c|c|c|c|c|}
\hline \multirow{2}{*}{ 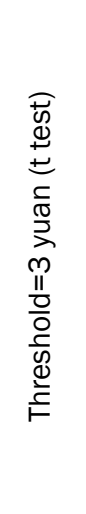 } & 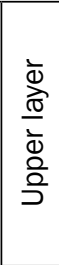 & 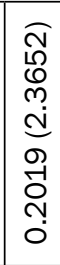 & 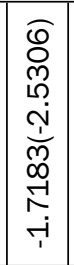 & 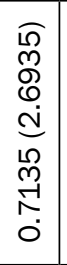 & 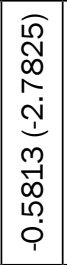 & 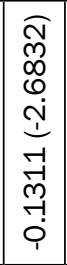 & 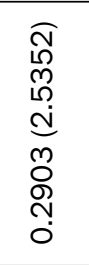 & 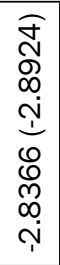 & 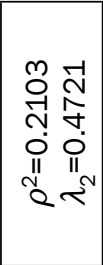 \\
\hline & $\begin{array}{l}\bar{े} \\
\overline{0} \\
\frac{0}{0} \\
\bar{\vdots}\end{array}$ & 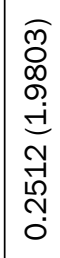 & 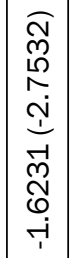 & 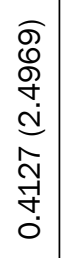 & 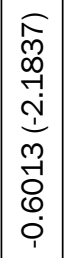 & 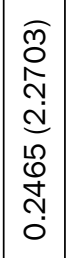 & 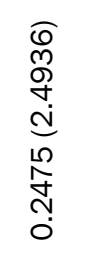 & I & 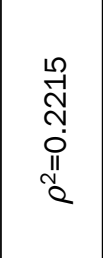 \\
\hline \multirow{2}{*}{ 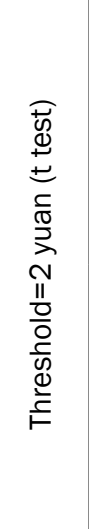 } & $\begin{array}{l}\frac{\bar{d}}{\grave{\sigma}} \\
\frac{\bar{\alpha}}{\bar{\phi}} \\
\stackrel{0}{0}\end{array}$ & 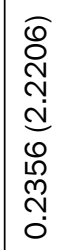 & 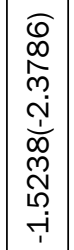 & 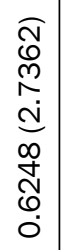 & 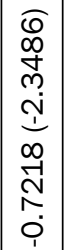 & 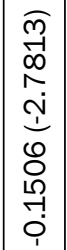 & 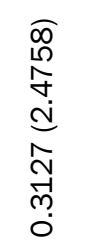 & 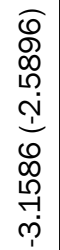 & 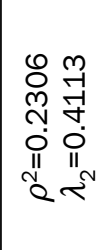 \\
\hline & $\begin{array}{l}\bar{d} \\
\stackrel{\bar{d}}{0} \\
\overline{0} \\
\bar{n}\end{array}$ & 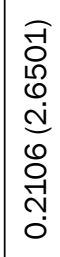 & 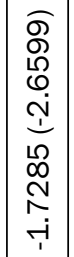 & 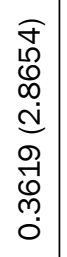 & 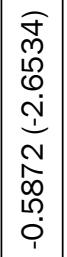 & 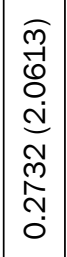 & 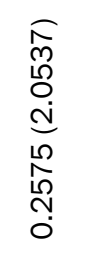 & ' & 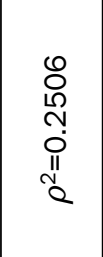 \\
\hline \multirow{2}{*}{ 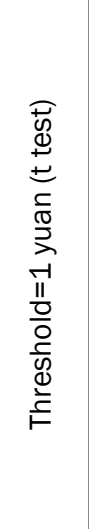 } & 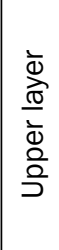 & 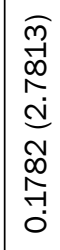 & 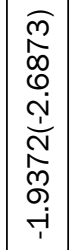 & 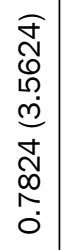 & 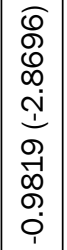 & 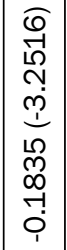 & 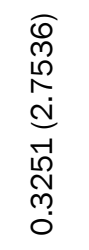 & 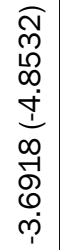 & 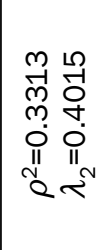 \\
\hline & $\begin{array}{l}\bar{\Phi} \\
\bar{\alpha} \\
\overline{0} \\
\overline{3} \\
\omega\end{array}$ & 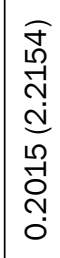 & 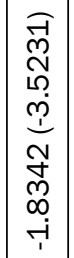 & 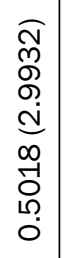 & 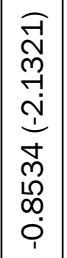 & 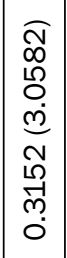 & 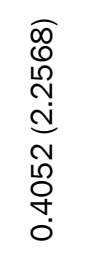 & ' & 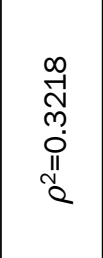 \\
\hline \multirow{2}{*}{ 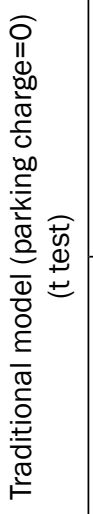 } & $\begin{array}{l}\overline{\bar{d}} \\
\frac{\bar{\sigma}}{\overline{0}} \\
\overline{\bar{d}} \\
\frac{0}{2}\end{array}$ & 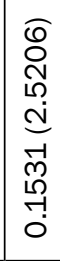 & 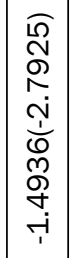 & 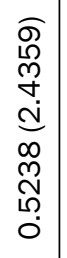 & 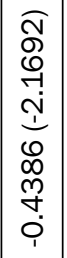 & 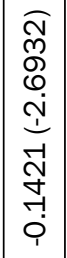 & & ' & 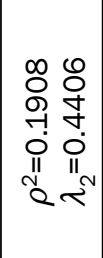 \\
\hline & $\begin{array}{l}\overline{\bar{d}} \\
\stackrel{\bar{\omega}}{0} \\
\overline{0} \\
\bar{\omega}\end{array}$ & 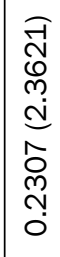 & 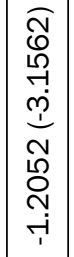 & 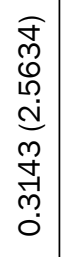 & 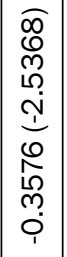 & 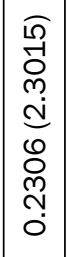 & & ' & 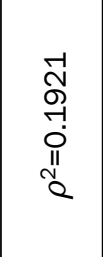 \\
\hline \multicolumn{2}{|c|}{ 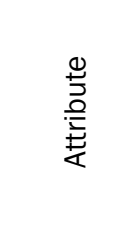 } & 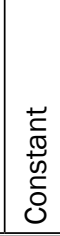 & 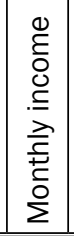 & $\begin{array}{l}\frac{\grave{d}}{0} \\
\bar{d} \\
\mathbb{0}\end{array}$ & 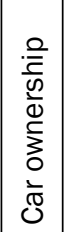 & 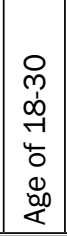 & 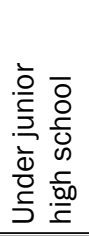 & 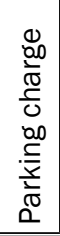 & 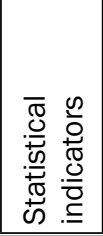 \\
\hline
\end{tabular}




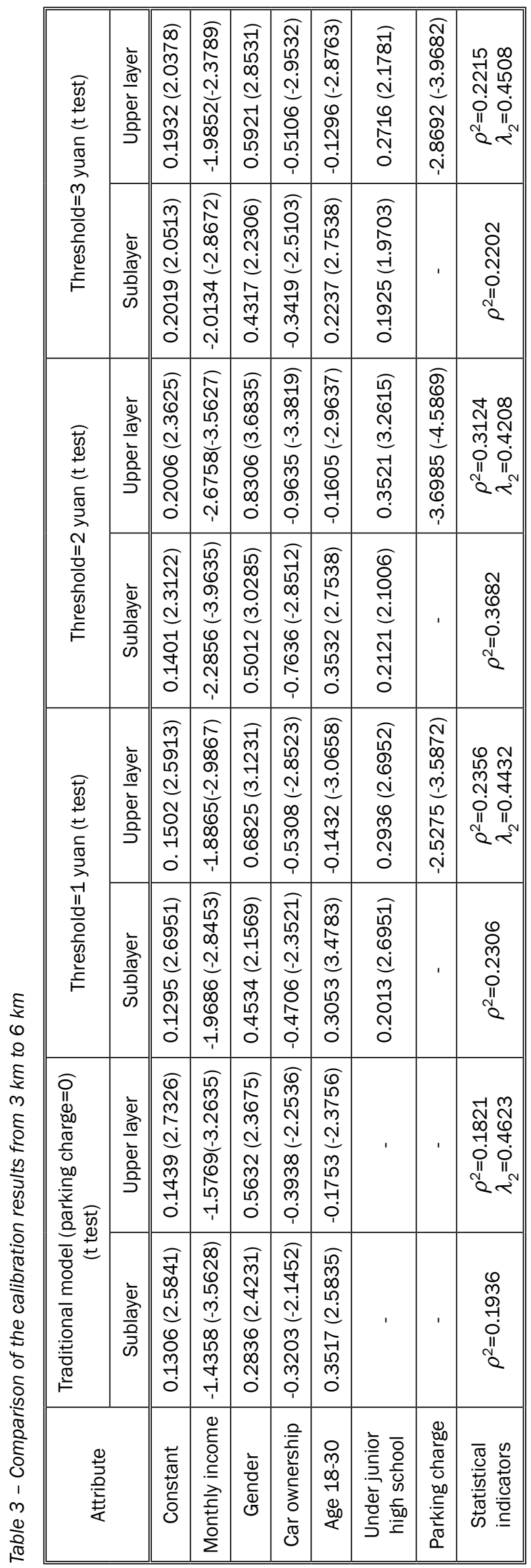

\begin{tabular}{|c|c|c|c|c|c|c|c|c|c|}
\hline \multirow{2}{*}{ 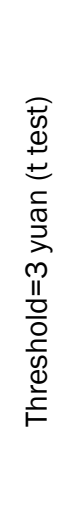 } & 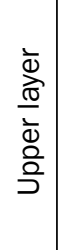 & 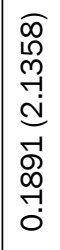 & 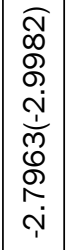 & \begin{tabular}{|l|}
$\pi$ \\
0 \\
0 \\
0 \\
0 \\
0 \\
0 \\
0 \\
$\tilde{N}$ \\
+ \\
0
\end{tabular} & 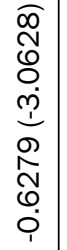 & 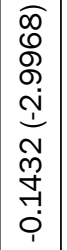 & 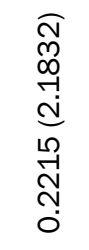 & 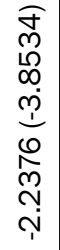 & 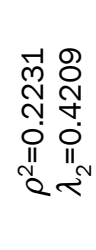 \\
\hline & $\begin{array}{l}\overline{\bar{d}} \\
\overline{\vec{\omega}} \\
\overline{0} \\
\bar{\omega}\end{array}$ & 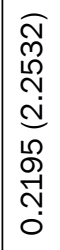 & 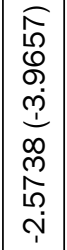 & \begin{tabular}{|l|}
$\widehat{9}$ \\
0 \\
1 \\
10 \\
$i \mathfrak{~}$ \\
$m$ \\
0 \\
0 \\
0 \\
0 \\
0
\end{tabular} & 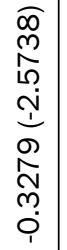 & 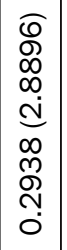 & 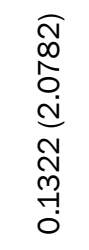 & , & 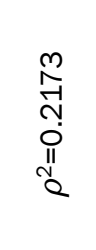 \\
\hline \multirow{2}{*}{ 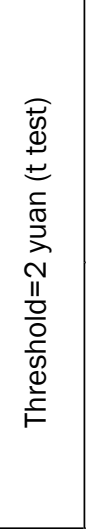 } & $\begin{array}{l}\frac{\bar{d}}{\Delta} \\
\frac{\sigma}{0} \\
\overline{\bar{d}} \\
\frac{0}{2} \\
\frac{\partial}{\partial}\end{array}$ & 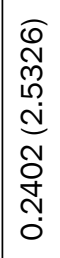 & 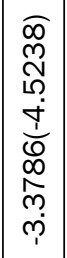 & 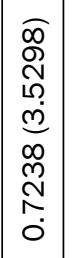 & 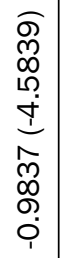 & 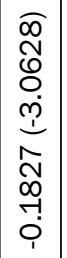 & 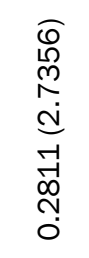 & 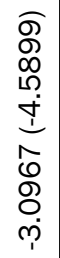 & 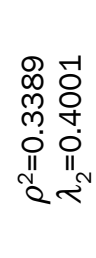 \\
\hline & $\begin{array}{l}\bar{d} \\
\bar{a} \\
\overline{0} \\
\overline{0} \\
\omega\end{array}$ & 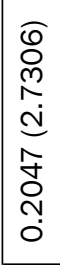 & 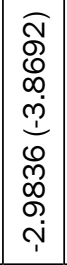 & 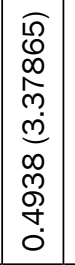 & 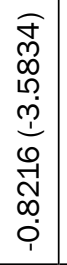 & 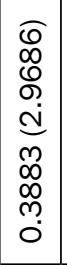 & 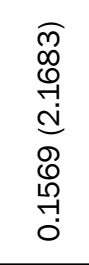 & ' & 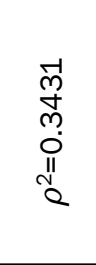 \\
\hline \multirow{2}{*}{ 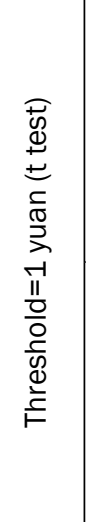 } & $\begin{array}{l}\frac{\bar{D}}{0} \\
\frac{0}{\overline{0}} \\
\frac{0}{\partial} \\
\frac{0}{\partial}\end{array}$ & 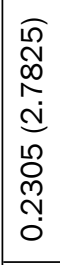 & 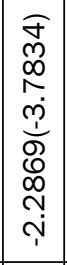 & 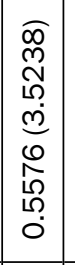 & 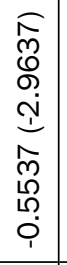 & 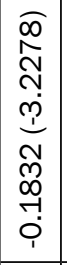 & 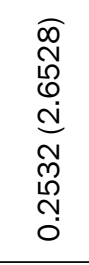 & 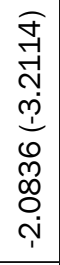 & 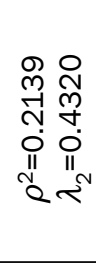 \\
\hline & $\begin{array}{l}\frac{\bar{D}}{\overline{0}} \\
\frac{0}{0} \\
\overline{0} \\
\overline{3}\end{array}$ & 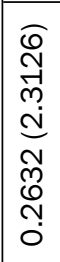 & 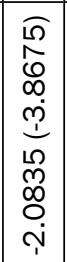 & 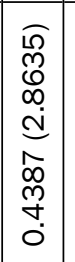 & 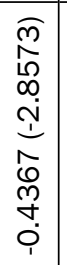 & 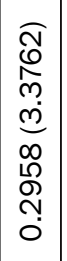 & 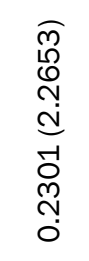 & I & 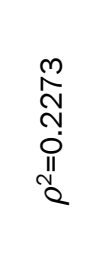 \\
\hline \multirow{2}{*}{ 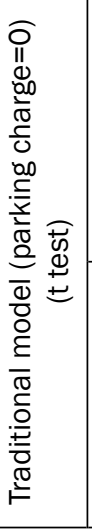 } & $\begin{array}{l}\overline{\bar{\omega}} \\
\frac{\bar{\sigma}}{\bar{\alpha}} \\
\overline{0} \\
\overline{0}\end{array}$ & 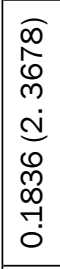 & 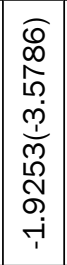 & 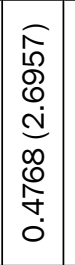 & 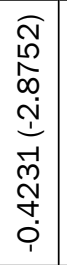 & 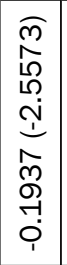 & & ' & 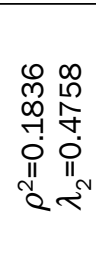 \\
\hline & 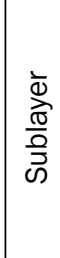 & 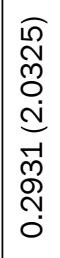 & 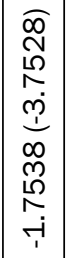 & 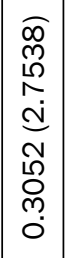 & 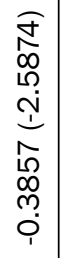 & 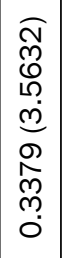 & & , & 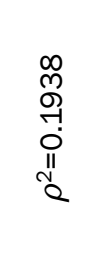 \\
\hline 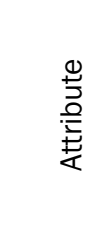 & & 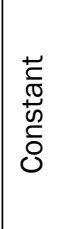 & 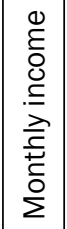 & $\begin{array}{l}\frac{\bar{d}}{\bar{c}} \\
\frac{\bar{d}}{\bar{d}}\end{array}$ & 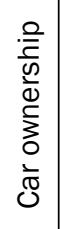 & 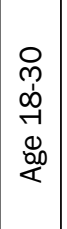 & 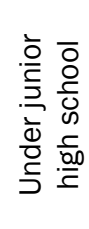 & 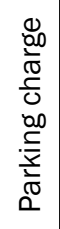 & 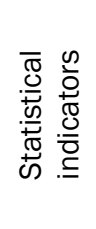 \\
\hline
\end{tabular}

